Case Report

\title{
Exophiala Pneumonia Presenting with a Cough Productive of Black Sputum
}

\author{
Yehuda Z. Cohen and Wendy Stead \\ Division of Infectious Diseases, Department of Medicine, Beth Israel Deaconess Medical Center, Harvard Medical School, \\ Boston, MA 02215, USA \\ Correspondence should be addressed to Yehuda Z. Cohen; ycohen@bidmc.harvard.edu
}

Received 7 January 2015; Accepted 20 April 2015

Academic Editor: Pere Domingo

Copyright (C) 2015 Y. Z. Cohen and W. Stead. This is an open access article distributed under the Creative Commons Attribution License, which permits unrestricted use, distribution, and reproduction in any medium, provided the original work is properly cited.

Exophiala species are black, yeast-like molds that can cause subcutaneous cysts as well as disseminated disease. Isolated pneumonia due to Exophiala species is extremely uncommon. We report a case of isolated Exophiala pneumonia in a patient with bronchiectasis who presented with worsening dyspnea and a cough productive of black sputum. The production of black sputum, known as melanoptysis, is an uncommon physical finding with a limited differential diagnosis. To our knowledge, this is the first reported case of Exophiala pneumonia presenting with a cough productive of black sputum.

\section{Introduction}

Exophiala species are dematiaceous (dark-pigmented) environmental fungi with a worldwide distribution. They are often described as black, yeast-like molds [1]. Infection with Exophiala species is uncommon but typically presents as subcutaneous cysts and can occur in both immunocompetent and immunocompromised individuals [2]. Disseminated disease is often neurotropic and carries a poor prognosis [3, 4]. Isolated pneumonia due to Exophiala species is extremely rare. Although Exophiala dermatitidis has been found to colonize the airways of up to $19 \%$ of patients with cystic fibrosis [5, 6], only a few cases of Exophiala dermatitidis pneumonia have been reported in that population [7-9]. A small number of cases of Exophiala dermatitidis pneumonia, as well as a single case of Exophiala jeanselmei pneumonia, have also been reported in patients without cystic fibrosis [10-13]. Here we present a case of Exophiala pneumonia in a patient with bronchiectasis who presented with a cough productive of black sputum.

\section{Case Presentation}

A 75-year-old woman with bronchiectasis was referred to the infectious diseases clinic with worsening dyspnea on exertion and a productive cough over the previous 3 months. She had been diagnosed with bronchiectasis about 30 years earlier and was doing well until 7 years prior to presentation when she was diagnosed with pulmonary Mycobacterium avium complex infection. She was treated with clarithromycin, rifampin, and ethambutol for over 2 years with improvement in symptoms. Over the next few years, dyspnea on exertion and mucus production slowly increased. During the 5 years prior to presentation, 12 respiratory cultures for acid-fast bacilli were performed, and all were negative. Seven fungal respiratory cultures were performed during this time as well, and all returned positive for Exophiala jeanselmei, which was thought to represent colonization. These isolates were identified based on morphology, which is known to be unreliable [14]. In the 3 months before presentation, dyspnea on exertion and cough significantly worsened, and the patient began to produce black sputum (Figure 1). Physical examination was unremarkable. A thoracic CT scan revealed bronchiectasis that was unchanged and new consolidations in the lower lobes. Sputum acid-fast culture was negative. Sputum fungal culture grew a black, yeast-like mold (Figure 2), which was again identified on the basis of morphological characteristics as Exophiala jeanselmei. Susceptibility testing demonstrated an MIC of $0.5 \mu \mathrm{g} / \mathrm{mL}$ for amphotericin B, $0.5 \mu \mathrm{g} / \mathrm{mL}$ for itraconazole, and $0.25 \mu \mathrm{g} / \mathrm{mL}$ for voriconazole. The patient 


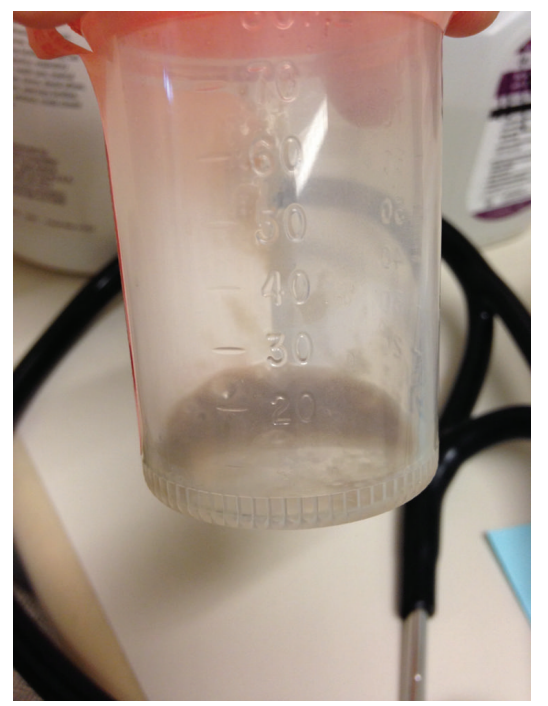

FIgURE 1

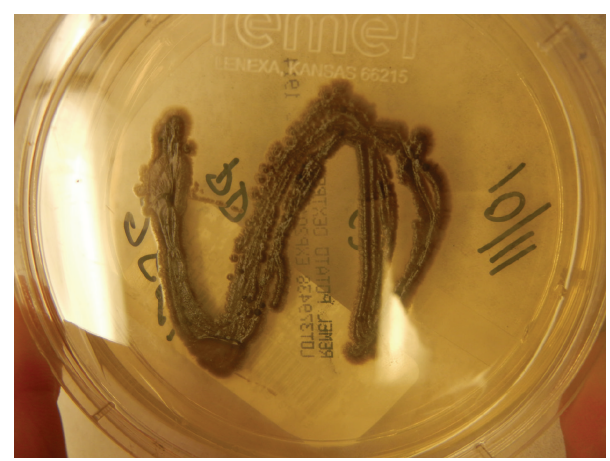

Figure 2

was started on $200 \mathrm{mg}$ of itraconazole daily. After 6 weeks of therapy, the patient was no longer producing black sputum and began to have some improvement in her symptoms. By 5 months of therapy, the patient had experienced a dramatic improvement in symptoms. Therapy was continued for a total of 6 months.

Three weeks after stopping itraconazole the patient again developed increased shortness of breath and cough productive of black sputum. Sputum fungal culture at that time grew an isolate morphologically identified as Exophiala dermatitidis. DNA sequencing of the ITS and D1/D2 regions confirmed the specimen to be Exophiala dermatitidis. Susceptibility testing revealed an MIC of $1 \mu \mathrm{g} / \mathrm{mL}$ for amphotericin $\mathrm{B}, 0.5 \mu \mathrm{g} / \mathrm{mL}$ for itraconazole, $0.25 \mu \mathrm{g} / \mathrm{mL}$ for posaconazole, $<0.03 \mu \mathrm{g} / \mathrm{mL}$ for voriconazole, and $0.015 \mu \mathrm{g} / \mathrm{mL}$ for terbinafine. The patient was started on voriconazole $200 \mathrm{mg}$ twice daily with improvement in symptoms and resolution of black sputum production, with a plan to continue therapy for at least one year. Therapy was stopped after 7 months when the patient developed alopecia and peripheral neuropathy. Posaconazole $300 \mathrm{mg}$ twice daily was started but discontinued after 2 months when additional neurologic symptoms developed. The patient opted not to pursue any further antifungal treatment at that time.

\section{Discussion}

Only a handful of cases of Exophiala pneumonia have been reported in the literature. These include 3 cases in patients with cystic fibrosis [7-9], 2 cases in patients with bronchiectasis [10,11], and 2 cases in patients without prior lung disease $[12,13]$. Exophiala dermatitidis is known to colonize the airways of individuals with cystic fibrosis, but no studies have been performed to investigate if Exophiala dermatitidis also commonly colonizes the airways of patients with noncystic fibrosis bronchiectasis. In our patient, Exophiala species had been present in respiratory cultures for 5 years prior to her presentation. It seems likely that the patient was colonized with this organism for many years and that infection only occurred in the few months before presentation when her symptoms considerably worsened, the production of black sputum began, and consolidations were found on CT. Treatment with antifungals resulted in improvement of symptoms and resolution of black sputum production.

In this patient, Exophiala isolates from sputum cultures were originally identified as Exophiala jeanselmei and later as Exophiala dermatitidis. DNA sequencing confirmed the later isolate to indeed be Exophiala dermatitidis. It appears unlikely that this patient had a mixed infection with 2 Exophiala species. The more likely scenario is that Exophiala dermatitidis was the sole etiologic agent, and the original isolates, which were identified on the basis of morphological characteristics only, were misidentified.

Although Exophiala species produce melanin and appear black, no prior reports of Exophiala pneumonia have mentioned black sputum as a presenting feature. The production of black sputum, termed melanoptysis, is an uncommon clinical finding in general and has a limited differential diagnosis. It appears to occur most often in coal miners with progressive massive fibrosis and cavitary pneumoconiosis [15]. It has also been described in smokers of alkaloid cocaine (crack) [16] and as a result of malignant melanoma [17]. Infection with another fungus that produces melanin, Aspergillus niger, has also been reported as a cause of melanoptysis [18]. Interestingly, a patient who presented with Exophiala dermatitidis subconjunctival mycetoma was reported to have black deposits in her tears [19].

In conclusion, isolated Exophiala pneumonia is a rare cause of pneumonia that appears to occur more frequently in individuals with cystic fibrosis or bronchiectasis. The production of black sputum, termed melanoptysis, is an uncommon physical finding. Exophiala pneumonia can be added to the differential diagnosis in patients who present with this unusual finding.

\section{Conflict of Interests}

The authors declare that there is no conflict of interests regarding the publication of this paper.

\section{Acknowledgments}

The authors thank David Roberts, M.D., and Terra Cederroth, M.D., for their photographs. 


\section{References}

[1] S. G. Revankar and D. A. Sutton, "Melanized fungi in human disease," Clinical Microbiology Reviews, vol. 23, no. 4, pp. 884928, 2010 .

[2] E. J. Sudduth, A. J. Crumbley III, and W. E. Farrar, "Phaeohyphomycosis due to Exophiala species: clinical spectrum of disease in humans," Clinical Infectious Diseases, vol. 15, no. 4, pp. 639-644, 1992.

[3] M. Hiruma, A. Kawada, H. Ohata et al., "Systemic phaeohyphomycosis caused by Exophiala dermatitidis," Mycoses, vol. 36, no. 1-2, pp. 1-7, 1993.

[4] R. T. Kenney, K. J. Kwon-Chung, A. Thomas Waytes et al., "Successful treatment of systemic exophiala dermatitidis infection in a patient with chronic granulomatous disease," Clinical Infectious Diseases, vol. 14, no. 1, pp. 235-242, 1992.

[5] N. Kondori, M. Gilljam, A. Lindblad, B. Jönsson, E. R. B. Moore, and C. Wennerås, "High rate of Exophiala dermatitidis recovery in the airways of patients with cystic fibrosis is associated with pancreatic insufficiency," Journal of Clinical Microbiology, vol. 49, no. 3, pp. 1004-1009, 2011.

[6] R. Horré, K. P. Schaal, R. Siekmeier, B. Sterzik, G. S. De Hoog, and N. Schnitzler, "Isolation of fungi, especially Exophiala dermatitidis, in patients suffering from cystic fibrosis: a prospective study," Respiration, vol. 71, no. 4, pp. 360-366, 2004.

[7] D. Diemert, D. Kunimoto, C. Sand, and R. Rennie, "Sputum isolation of Wangiella dermatitidis in patients with cystic fibrosis," Scandinavian Journal of Infectious Diseases, vol. 33, no. 10, pp. 777-779, 2001.

[8] G. Haase, H. Skopnik, and G. Kusenbach, "Exophiala dermatitidis infection in cystic fibrosis," The Lancet, vol. 336, no. 8708, pp. 188-189, 1990.

[9] G. Kusenbach, H. Skopnik, G. Haase, F. Friedrichs, and H. Döhmen, "Exophiala dermatitidis pneumonia in cystic fibrosis," European Journal of Pediatrics, vol. 151, no. 5, pp. 344-346, 1992.

[10] J. Barenfanger, F. Ramirez, R. P. Tewari, and L. Eagleton, "Pulmonary phaeohyphomycosis in a patient with hemoptysis," Chest, vol. 95, no. 5, pp. 1158-1160, 1989.

[11] T. Mukaino, T. Koga, Y. Oshita, Y. Narita, S. Obata, and H. Aizawa, "Exophiala dermatitidis infection in non-cystic fibrosis bronchiectasis," Respiratory Medicine, vol. 100, no. 11, pp. 20692071, 2006.

[12] Y. Mukai, S. Nureki, M. Hata et al., "Exophiala dermatitidis pneumonia successfully treated with long-term itraconazole therapy," Journal of Infection and Chemotherapy, vol. 20, no. 7, pp. 446-449, 2014.

[13] F. A. Manian and M. J. Brischetto, "Pulmonary infection due to Exophiala jeanselmei: successful treatment with ketoconazole," Clinical Infectious Diseases, vol. 16, no. 3, pp. 445-446, 1993.

[14] J. S. Zeng, D. A. Sutton, A. W. Fothergill, M. G. Rinaldi, M. J. Harrak, and G. S. de Hoog, "Spectrum of clinically relevant Exophiala species in the United States," Journal of Clinical Microbiology, vol. 45, no. 11, pp. 3713-3720, 2007.

[15] J. A. Mosquera, "Massive melanoptysis: a serious unrecognized complication of coal worker's pneumoconiosis," European Respiratory Journal, vol. 1, no. 8, pp. 766-768, 1988.

[16] D. P. Tashkin, D. Gorelick, M. E. Khalsa, M. Simmons, and P. Chang, "Respiratory effects of cocaine freebasing among habitual cocaine users," Journal of Addictive Diseases, vol. 11, no. 4, pp. 59-70, 1992.
[17] J. Eide, "Pathogenesis of generalized melanosis with melanuria and melanoptysis secondary to malignant melanoma," Histopathology, vol. 5, no. 3, pp. 285-294, 1981.

[18] M. Korzeniowska, H. Halweg, I. Bestry et al., "Pulmonary aspergilloma caused by Aspergillus niger," Pneumonologia Polska, vol. 58, pp. 328-333, 1990.

[19] E. Y. Li, H. K. Yuen, and D. C. Lung, "Subconjunctival mycetoma as an unusual cause of tears with black deposits," Archives of Ophthalmology, vol. 128, no. 10, pp. 1371-1372, 2010. 


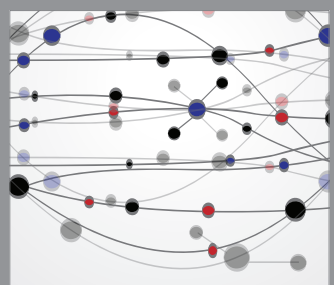

The Scientific World Journal
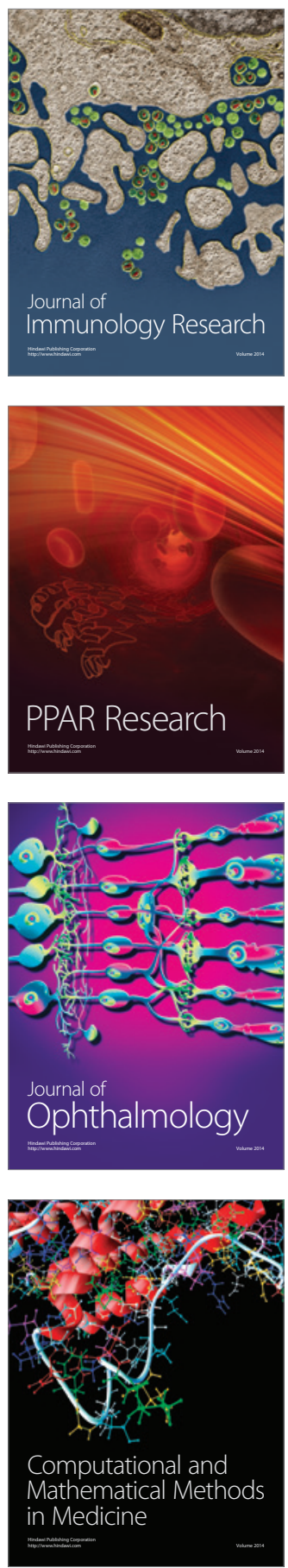

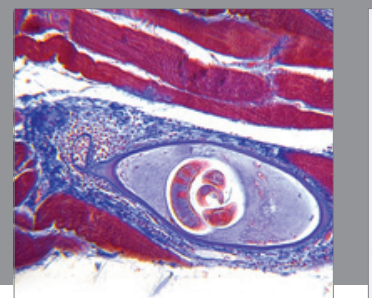

Gastroenterology

Research and Practice
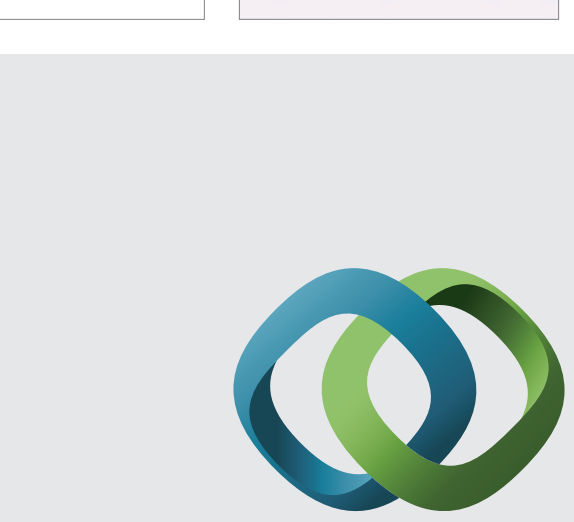

\section{Hindawi}

Submit your manuscripts at

http://www.hindawi.com
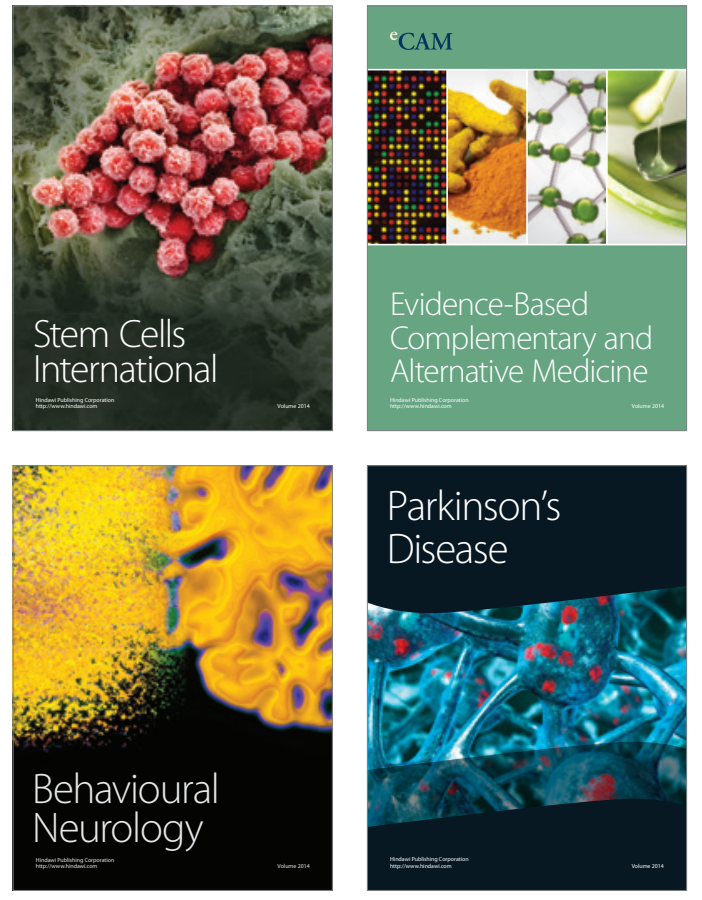
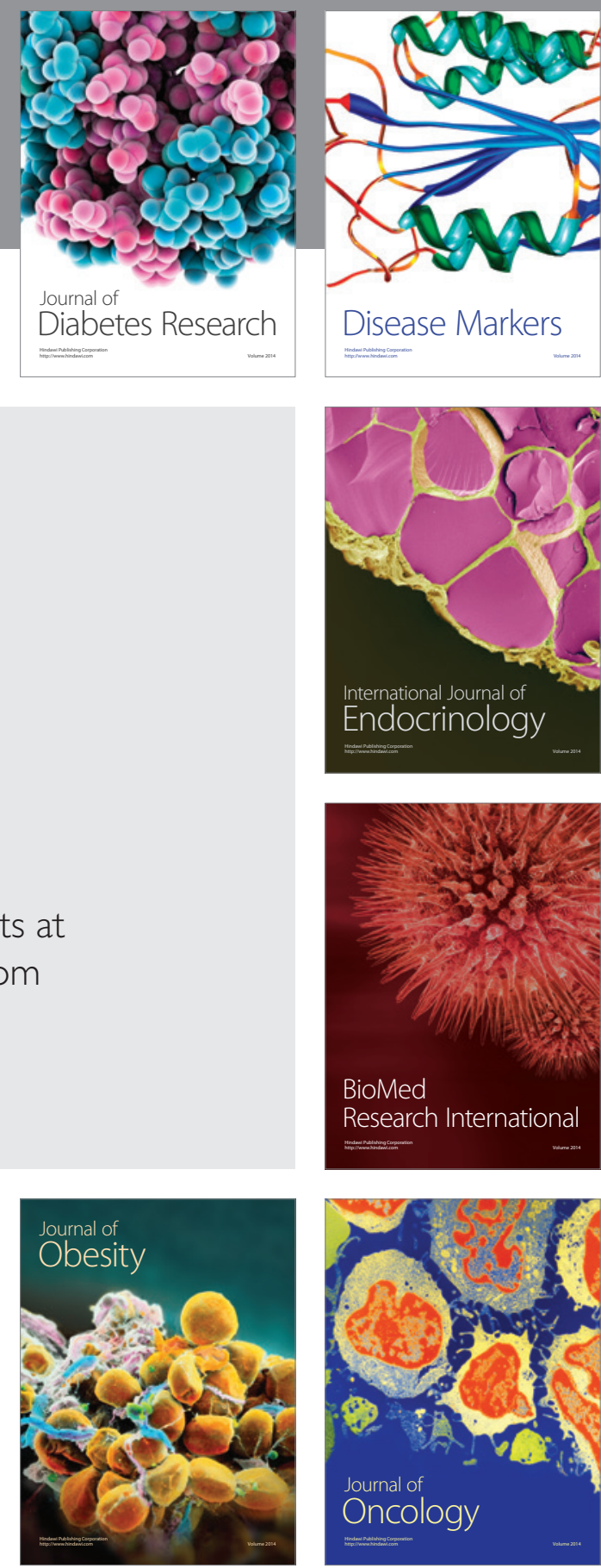

Disease Markers
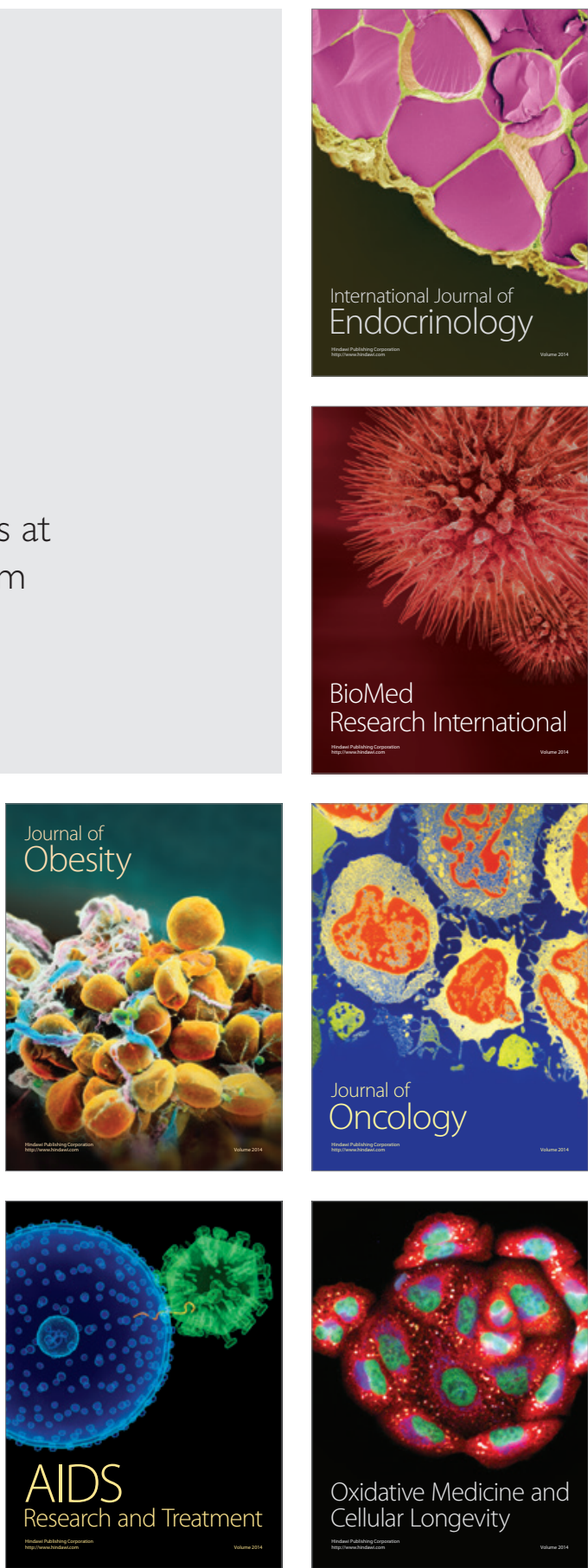